\title{
Efeito do nitrogênio em cobertura na produtividade de girassol, no Estado do Tocantins
}

\author{
Effect of top dressing nitrogen on sunflower yield, in the state of \\ Tocantins, Brazil
}

\section{Cleuton Ribeiro de OLIVEIRA'; Juara Leme de OLIVEIRA ${ }^{2}$; Felipe Rodrigues BARBOSA Alex Sandro DARIO ${ }^{4}$; Stefany Gregory MOURA ${ }^{5}$; Hélio Bandeira BARROS ${ }^{6}$}

\begin{abstract}
${ }^{1}$ Autor para correspondência - Eng. Agr. Mestrando em Produção Vegetal, Departamento de Agronomia, UFT, Universidade Federal Tocantins, Caixa Postal 66, 77402-970; Gurupi - TO. E-mail: cleutonxs@hotmail.com ${ }^{2}$ Acadêmico do curso de Agronomia - Universidade Federal Tocantins. E-mail: juaraleme@gmail.com

${ }^{3}$ Acadêmico do curso de Agronomia - Universidade Federal Tocantins. E-mail: felipe-agro@hotmail.com

${ }^{4}$ Acadêmico do curso de Agronomia - Universidade Federal Tocantins. E-mail: alexsandrodario@gmail.com ${ }^{5}$ Eng. Agrônomo - Universidade Federal Tocantins. E-mail: s.g.moura@hotmail.com

${ }^{6}$ Prof.Dr.; Professor da Universidade Federal Tocantins, UFT, Programa de Pós-Graduação em Produção Vegetal. E-mail: barroshb@mail.uft.edu.br
\end{abstract}

Recebido em: 24-11-2013; Aceito em: 29-04-2014

\section{Resumo}

Objetivou-se avaliar respostas de híbridos de girassol sob doses de nitrogênio, em época de segunda safra, em 2013, na região sul do Estado do Tocantins. O experimento foi conduzido na área experimental da Universidade Federal do Tocantins, Câmpus de Gurupi - TO. O delineamento estatístico adotado foi o de blocos ao acaso, no esquema fatorial $3 \times 5$, com cinco repetições. $O$ primeiro fator correspondeu aos híbridos (Helio 250, Helio 251 e Helio 360), o segundo, às cinco doses de nitrogênio em cobertura $\left(0 ; 50 ; 100 ; 150\right.$ e $\left.200 \mathrm{~kg} \mathrm{ha}^{-1}\right)$. As características agronômicas avaliadas foram: número de folhas, altura da planta, altura da inserção do capítulo, diâmetro da haste, diâmetro do capítulo, porcentagem de aquênios normais, massa de mil aquênios, densidade de grãos, número de aquênios por capítulo e produtividade. O híbrido H 251 mostrou-se, em média, superior aos demais, quanto ao diâmetro de capítulo, aquênios normais, número de aquênios por capítulo e produtividade. As variáveis altura da planta, altura do capítulo e diâmetro da haste aumentaram linearmente em função das doses de nitrogênio para todos os híbridos. Diâmetro do capítulo e aquênios normais obtiveram equações lineares e quadráticas. A adubação nitrogenada influenciou sobre as características altura de planta, altura de capítulo, diâmetro da haste, diâmetro do capítulo e número de aquênios por capítulo. O H251 obteve características agronômicas favoráveis para a produção no Estado do Tocantins, obtendo destaque em produtividade.

Palavras-chave adicionais: adubação nitrogenada; aquênio; Helianthus annuus L.

\begin{abstract}
The objective of this study was to evaluate responses of sunflower hybrids to nitrogen doses during the second crop season of 2013, in the southern region of the state of Tocantins, Brazil. The experiment was conducted in the experimental farm of the Federal University of Tocantins, campus Gurupi. The statistical design was a randomized complete block in a $3 \times 5$ factorial, with five replications. The first factor was the hybrids 'Helio 250', 'Helio 251', and 'Helio 360 and the second the nitrogen doses of $0,50,100,150$, and $200 \mathrm{~kg} \mathrm{ha}^{-1}$. The evaluated agronomic traits were the number of leaves, plant height, height of chapter insertion, stem diameter, chapter diameter, percentage of normal achenes, thousand achenes weight, grain density, number of achenes per chapter, and productivity. Hybrid 'Helio 251' mean performance was superior to that of the other hybrids as to chapter diameter, normal achenes, number of achenes per chapter, and productivity. In all hybrids plant height, chapter insertion height, and stem diameter increased linearly with nitrogen doses. Chapter diameter and normal achenes responded linearly and quadratically to nitrogen doses. Nitrogen fertilization influenced plant height, chapter height, stem diameter, and number of achenes per chapter. Hybrid 'H251' responded adequately to the environmental conditions prevailing in Tocantis state specifically in terms of productivity.
\end{abstract}

Additional keywords: achene; Helianthus annuus L.; nitrogen fertilization. 


\section{Introdução}

A área cultivada com girassol (Helianthus annuus L.) no Brasil é de aproximadamente $69.000 \mathrm{ha}^{-1}$, concentrada principalmente na região dos Cerrados (CONAB, 2013). LOPES et al. (2009) destacam que o girassol está entre as espécies vegetais de maior potencial para a produção de energia renovável no Brasil, como matéria-prima para a produção de biocombustível, constituindo também uma importante opção para sistemas envolvendo rotação ou sucessão de culturas.

Segundo CASTRO \& FARIAS (2005), pode ser cultivada em todas as regiões do País, pois o rendimento é pouco influenciado pelas latitudes, altitudes e fotoperíodo, o que facilita a expansão do cultivo no Brasil. É uma planta que se adapta bem a diversas condições edafoclimáticas, caracterizando-se pela relativa tolerância a déficits hídricos. CASTRO et al. (1996) citam que o crescimento dessa cultura é lento na fase inicial até o aparecimento do botão floral, consumindo baixas quantidades de água e nutrientes; todavia, a partir desse período até a fase R9 (maturação dos aquênios), há um intenso consumo de água e nutrientes, culminando com o crescimento da planta.

BRAZ \& ROSSETTO (2010) destacam que o acúmulo de nutrientes nas plantas de girassol é um dos fatores que contribuem para elevada produção. OLIVEIRA et al. (2005) constataram que a quantidade total extraída de $\mathrm{N}$ na parte aérea para uma produção de $3.176 \mathrm{~kg}$ de aquênios ha-1 foi de $130 \mathrm{~kg} \mathrm{ha}^{-1}$ de $\mathrm{N}$, até o período do florescimento. Segundo CASTRO \& FARIAS (2005), o período entre 56 e 84 dias após a emergência para o híbrido Helio 251 ocorreu o acúmulo máximo de nutriente, correspondendo às fases de florescimento e enchimento de aquênios.

O nitrogênio desempenha importante função no metabolismo e na nutrição da cultura do girassol, e sua omissão causa a desbalanceamento nutricional, reduzindo significativamente o desenvolvimento das plantas, afetando o número de folhas, a altura das plantas, o diâmetro do caule e a área foliar, e seu excesso causa decréscimo na porcentagem de óleo (BISCARO et al., 2008; PRADO \& LEAL, 2006). A dose e a época de aplicação constituem um fator importante na determinação do rendimento do girassol (CARVALHO; PISSAIA, 2002).

A deficiência do nitrogênio no final da fase vegetativa e no início da fase reprodutiva no girassol pode determinar uma redução no número de aquênio, que é o reflexo da ação do nitrogênio na fase de diferenciação floral, e por decorrência afeta também o diâmetro do capítulo (ZAGONEL \& MUNDSTOCK, 1991). IVANOFF et al. (2010) destacam que, em função das transformações no solo, como volatilização e lixiviação, o $\mathrm{N}$ tem gerado muitas controvérsias com relação à sua época de aplicação, e sendo aplicado de uma só vez, ou parceladamente, pode ser mais ou menos eficiente.

Para o milho, aplicações mais tardias do nitrogênio, duas a três semanas antes da floração, determinaram os melhores rendimentos em grãos, uma vez que o $\mathrm{N}$ é fornecido à planta na época em que sua absorção é máxima (SILVA \& SILVA, 2003). RAJKVIC et al. (1980) destacam que a resposta da planta ao $\mathrm{N}$ depende do solo e da cultivar. Devido à grande diversidade genética, o estudo dos híbridos de girassol mais adequados para cada região é essencial (MELLO et al., 2006). SANTOS et al. (2012) destacam que existe poucos estudos sobre a produção de Girassol no Estado do Tocantins.

A resposta do $\mathrm{N}$ é bastante dependente de condições adequadas para a absorção da planta, assim como o volume aplicado, tornando necessário um estudo que contemple a dose ideal para a produção dessa cultura. Diante disso, objetivou-se avaliar a resposta de híbridos de girassol sob doses de nitrogênio, em segunda safra, no Estado do Tocantins.

\section{Material e métodos}

O experimento foi conduzido na área experimental da Universidade Federal do Tocantins-Câmpus de Gurupi, localizada a $11^{\circ} 43^{\prime} 45^{\prime \prime}$ de latitude sul e $49^{\circ} 04^{\prime}$ '07" de longitude oeste e altitude de $280 \mathrm{~m}$, em um Latossolo VermelhoAmarelo distrófico (EMBRAPA, 2006). Os dados referentes às precipitações, temperatura e umidade relativa semanal, no período de condução do experimento, foram coletados na estação meteorológica do Câmpus de Gurupi, e são apresentados na Figura 1.

O delineamento experimental utilizado foi 0 de blocos casualizados, em esquema fatorial $3 \times 5$, com cinco repetições. O primeiro fator correspondeu a três híbridos de girassol, sendo o Helio 250 (H250), Helio 251 (H251) e Helio 360 (H360). O segundo fator foram as cinco doses de nitrogênio, sendo $0 ; 50 ; 100 ; 150$ e $200 \mathrm{~kg} \mathrm{ha}^{-1}$, na forma de ureia $(45 \%$ de $\mathrm{N}$ ), totalizando 15 tratamentos e 75 parcelas. O espaçamento adotado foi $0,30 \mathrm{~m}$ entre plantas e $0,45 \mathrm{~m}$ entre linhas, no total de 8 linhas por parcela, totalizando uma população de 68.965 plantas por hectare. Foram consideradas as 4 linhas centrais, sendo a área útil de $7,2 \mathrm{~m}^{2}$. 


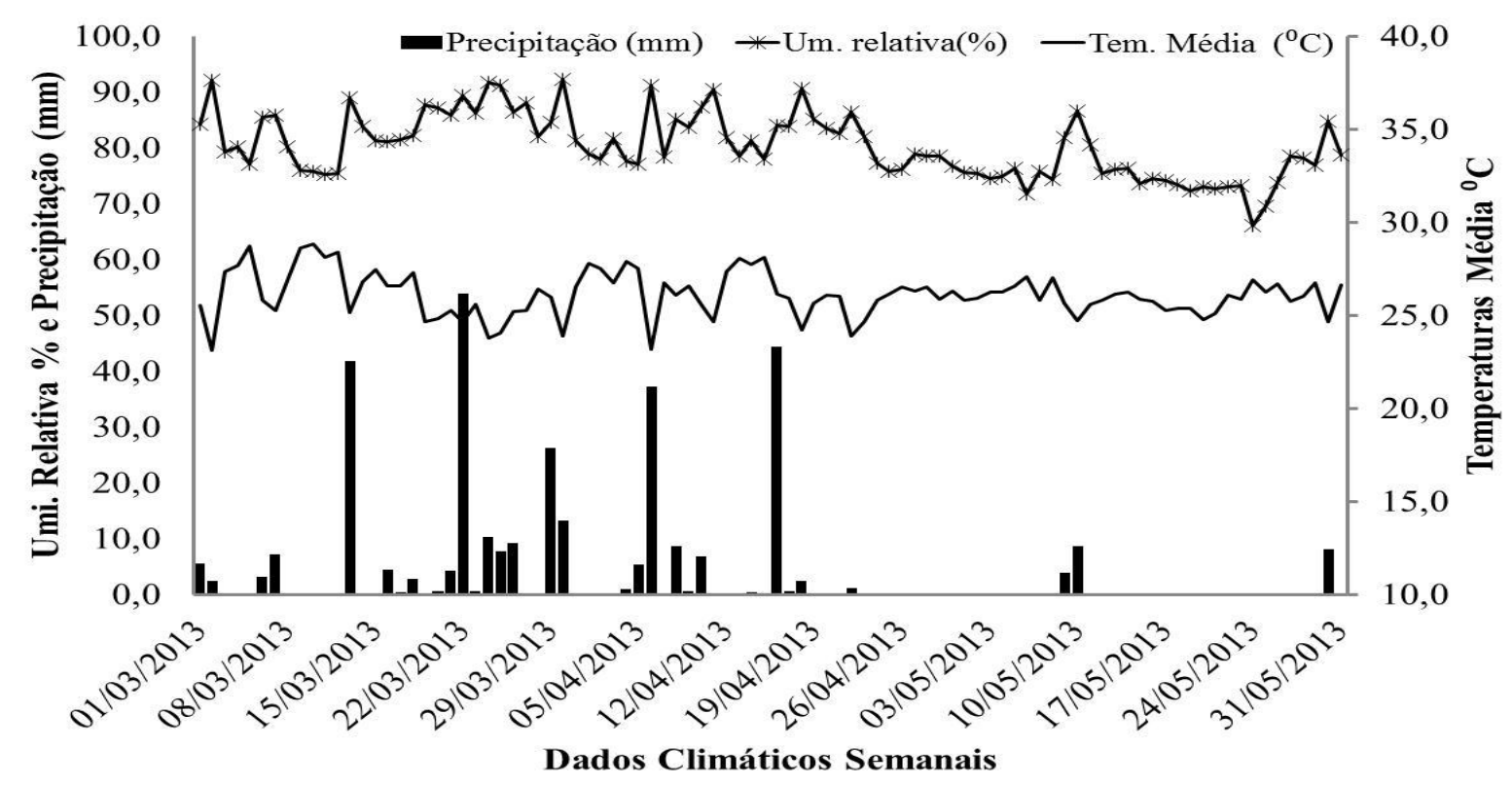

Figura 1 - Dados climáticos semanal de temperatura média $\left({ }^{\circ} \mathrm{C}\right)$, umidade relativa do ar $(\%)$ e precipitação pluvial $(\mathrm{mm})$ durante o período de 01 de março a 31 de maio de 2013, Gurupi - TO. Weekly mean data of temperature ( $\left.{ }^{\circ} \mathrm{C}\right)$, relative humidity (\%), and rainfall $(\mathrm{mm})$ from March 1 to May $31^{\text {st }}, 2013$, in Gurupi, state of Tocantins, Brazil.

Antes da instalação do ensaio, realizouse o preparo do solo no sistema de plantio convencional, com posterior dessecação, empregando o equivalente a 3,0 $\mathrm{L} \mathrm{ha}^{-1}$ de glifosato. A adubação de plantio foi aplicada no sulco de semeadura, utilizando $500 \mathrm{~kg} \mathrm{ha}^{-1}$ da formulação 05- 25-15. As adubações de cobertura foram realizadas aos 12 e 31 dias após a emergência (DAE), com aplicação do nitrogênio correspondendo a 40 e $60 \%$ das doses, respectivamente. Aplicou-se via foliar 1,0 $\mathrm{L} \mathrm{ha}^{-1}$ de boro na forma de ácido bórico, aos $30 \mathrm{DAE}$, usando volume de calda de $100 \mathrm{~L} \mathrm{ha}^{-1}$.

Antes da instalação do experimento, realizou-se a amostragem do solo na camada de 0-20 para a análise química e física, segundo a metodologia EMBRAPA (1997), e os resultados foram: $\mathrm{pH}\left(\mathrm{CaCl}_{2}\right)=5,1 \mathrm{Ca}=1,4 \mathrm{cmolc} \mathrm{dm}^{-3} ; \mathrm{Mg}=$ $0,5 \mathrm{cmolc} \mathrm{dm}^{-3} ; \quad \mathrm{P}=24,3 \mathrm{mg} \mathrm{dm}^{-3} ; \mathrm{K}=$ $107,0 \mathrm{mg} \mathrm{dm}^{-3} ; \quad \mathrm{H}=2,0 \mathrm{cmolc} \mathrm{dm}^{-3} \mathrm{Al}=$ $0,0 \mathrm{cmolc} \mathrm{dm}^{-3} ; \mathrm{V} \%=52,00 ; \mathrm{MO}=11,0 \mathrm{~g} \mathrm{dm}^{-3}$; areia $=67 \%$; silte $=7 \%$; argila $=26 \%$.

A semeadura foi realizada em 23 de fevereiro de 2013, e a germinação plena ocorreu sete dias após a semeadura DAE. Aos 10 DAE foi realizado o desbaste, proporcionando uma população final de plantas de 68.965 plantas ha ${ }^{-1}$. Para evitar o efeito de plantas daninhas sobre o desenvolvimento dos híbridos de girassol, foi realizada uma aplicação com herbicida Cletodim, aos 16 dias após o plantio, e uma capina manual aos 25 DAE.

As características avaliadas foram: nú- meros de folhas (NF), contadas em cinco plantas por parcela ao atingirem o estádio fenológico R4; altura da planta $(\mathrm{AP}, \mathrm{em} \mathrm{cm})$ medida do colo da planta até a inserção do capítulo, em cinco plantas; altura da inserção do capítulo (AC, em $\mathrm{cm})$, medida a partir do solo até o ponto central do capítulo, em cinco plantas competitivas da parcela útil; diâmetro da haste $(\mathrm{DH}$, em $\mathrm{mm})$, medido a $10 \mathrm{~cm}$ do solo, em cinco plantas da parcela, utilizando-se de paquímetro; diâmetro do capítulo (DC, em cm), medido em cinco capítulos de cada parcela útil; aquênios normais (AN, em \%), contados em cinco capítulos de cada parcela útil; densidade de grãos (DG, em $\mathrm{kg} \mathrm{m}^{3}$ ), quantificação da massa em volume conhecido com posterior extrapolação para 1.000 litros; número de aquênios por capítulo (NAC), obtido em cinco capítulos; massa de mil aquênios (P1.000, em g), obtida pela contagem de 1.000 aquênios de cinco capítulos, pesados posteriormente em balança de precisão, e produtividade de aquênios (PROD, em kg ha-1), considerandose todas as plantas da área útil, e todas as amostras tiveram correção de umidade de $11 \%$.

Os dados foram submetidos à análise individual e conjunta de variância, com aplicação do teste F. A análise conjunta foi realizada sob condições de homogeneidade das variâncias residuais. Para as comparações entre médias de tratamentos, foi utilizado o teste de Tukey $(P \leq 0,05)$, e em todas as variáveis foi utilizado o aplicativo computacional em genética e estatística - GENES (CRUZ, 2006). 
Realizou-se a análise de regressão para efeito das doses de Nitrogênio. A escolha do modelo selecionado para cada variável baseouse na significância das variáveis e nos valores do R2 (ALVAREZ, V.; ALVAREZ, 2006). O teste F foi utilizado para testar os coeficientes da regressão no mesmo nível de probabilidade. Empregou-se para análise dos dados o programa estatístico SigmaPlot 10.0 (Sigmaplot, 2007).

\section{Resultados e discussão}

Não se verificou interação significativa entre os tratamentos testados (Tabela 1). Verificou-se diferença $(p \leq 0,01)$ para os híbridos para $\mathrm{NF}, \mathrm{AP}, \mathrm{AC}, \mathrm{P} 1.000$, DG, NAC, PROD e para DH a $(p \leq 0,05)$. Não houve significância para DC e AN\%. Para doses de $\mathrm{N}$, não constatou diferença significativa para NF, AN\%, P1.000, DG e PROD. Entretanto, houve efeitos $(p \leq 0,01)$ para as demais características avaliadas.

As médias comparadas pelo teste de Tukey estão dispostas na Tabela 2. Não houve diferença entre os híbridos para número de foIhas. Isto pode ter ocorrido, possivelmente, por interferência da população de plantas e do espaçamento utilizados no experimento, que pode ter influenciado na competição por luminosidade. Segundo ANDRADE et al. (2002), a utilização de altas populações em espaçamentos reduzidos tem como objetivo melhorar a interceptação da radiação solar e garantir o controle de plantas daninhas, desde que não haja déficit hídrico nem nutricional. AQUINO et al. (2013), estudando os mesmos híbridos com espaçamento superior e população inferior, obtiveram menores valores para esta característica.

Altura de planta e do capítulo apresentaram a mesma tendência, obtendo o híbrido H251 maiores valores, diferindo significativamente dos demais. SILVA et al. (2009), estudando o híbrido H251 em espaçamentos reduzidos de 40 e $50 \mathrm{~cm}$, respectivamente, obtiveram altura média de $97,1 \mathrm{~cm}$, inferior ao encontrado no presente trabalho. SILVA et al. (2007), ao avaliar o crescimento e a produtividade do girassol com diferentes lâminas de água obtiveram, com mesma precipitação, resultados inferiores para os híbridos H250 e H251. AQUINO et al. (2013) obtiveram resultado semelhante para altura de planta, estudando os mesmos híbridos avaliados.

Não foi verificada diferença significativa entre híbridos para o diâmetro do capítulo (Tabela 2). CADORIN et al. (2012), ao avaliar características de plantas em função da época de semeadura, obtiveram valores superiores aos encontrados no presente estudo, que pode ser explicado pelo maior espaçamento e menor população de plantas, consequentemente, menor altura de plantas. Esses valores podem ser consequência da competição das plantas pelo espaçamento reduzido, aliado à baixa precipitação ocorrida no período de condução do experimento (Figura 1).

Tabela 1 - Resumo da análise de variância conjunta, das características número de folhas (NF); altura de plantas (AP); altura do capítulo (AC); diâmetro da haste (DH); diâmetro de capítulo (DC); aquênios normais (AN); peso de mil aquênios (P1.000); densidade de Grão (DG); número de aquênios capítulo (NAC); produtividade de aquênios (PROD), de três híbridos de girassol sob influência de doses de N, Gurupi - TO, segunda safra de 2013. Summary of combined analysis of variance of the characteristics number of leaves (NF); plant height (AP); chapter height (AC); stem diameter (DH); chapter diameter (DC); normal achenes (AN); weight of a thousand achenes (P1000); grain density (DG); number of achenes per chapter (NAC); achenes yield (PROD), of three sunflower hybrids under the influence of N levels, Gurupi - TO, second crop season of 2013.

\begin{tabular}{|c|c|c|c|c|c|c|}
\hline \multirow{2}{*}{$\begin{array}{c}\text { Fontes de } \\
\text { variação }\end{array}$} & \multicolumn{6}{|c|}{ Quadrado Médio } \\
\hline & G.L & NF & AP & $A C$ & $\mathrm{DH}$ & $\mathrm{DC}$ \\
\hline Cultivar & 2 & $9,2^{* *}$ & $2578,1^{* *}$ & $2595,8^{* *}$ & $4,3^{*}$ & $4,2^{\mathrm{ns}}$ \\
\hline Dose N & 4 & $3,6^{\mathrm{ns}}$ & $879,5^{\star *}$ & $894,7^{* *}$ & $11,6^{\star *}$ & $3,8^{* *}$ \\
\hline Cult x DN & 8 & $1,2^{\mathrm{ns}}$ & $47,9^{\text {ns }}$ & $49,4^{\mathrm{ns}}$ & $0,9^{\text {ns }}$ & $1,2^{\text {ns }}$ \\
\hline Resíduo & 56 & 1,8 & 98,1 & 94,6 & 3,5 & 0,6 \\
\hline CV (\%) & & 4,2 & 5,8 & 5,6 & 10,8 & 5,3 \\
\hline \multirow{2}{*}{$\begin{array}{l}\text { Fontes de } \\
\text { variação }\end{array}$} & \multicolumn{6}{|c|}{ Quadrado Médio } \\
\hline & $\mathrm{GL}$ & AN & P1000 & $\mathrm{DG}$ & NAC & PROD \\
\hline Cultivar & 2 & $4,6^{\mathrm{ns}}$ & $694,1^{\star *}$ & $13779,9^{\star *}$ & $735245,6^{\star \star}$ & $1665962,1^{* *}$ \\
\hline Dose N & 4 & $25,1^{\mathrm{ns}}$ & $27,1^{\text {ns }}$ & $1729,9^{\text {ns }}$ & $98228,2^{* *}$ & $61165,4^{\mathrm{ns}}$ \\
\hline Cult x DN & 8 & $5,7^{\mathrm{ns}}$ & $21,5^{\mathrm{ns}}$ & $663,2^{\text {ns }}$ & $9851,1^{\mathrm{ns}}$ & $15236,4^{\text {ns }}$ \\
\hline Resíduo & 56 & 13,3 & 31,7 & 4332,3 & 26723,2 & 34369,9 \\
\hline CV (\%) & & 4,1 & 18,1 & 29,2 & 16,0 & 11,6 \\
\hline
\end{tabular}


Tabela 2 - Número de Folhas (NF); altura de plantas (AP); altura do capítulo (AC); diâmetro de capítulo (DC); diâmetro da haste (DH); aquênios normais (AN); peso de mil aquênios (P1000); Densidade de Grãos (DG); número de aquênios capítulo (NAC); produtividade (PROD), de três híbridos de girassol, Gurupi - TO, segunda safra de 2013. Number of Leaves (NF); plant height (AP); chapter height (AC); chapter diameter (DC); stem diameter (DH); normal achenes (AN); weight of a thousand achenes (P1000); grain density (DG); number of achenes per chapter (NAC); productivity (PROD), of three sunflower hybrids, Gurupi - TO, second crop season of 2013.

\begin{tabular}{|c|c|c|c|c|c|c|c|c|c|c|}
\hline \multirow{2}{*}{ Cultivar } & $\mathrm{NF}$ & $\overline{\mathrm{AP}}$ & $\overline{A C}$ & $\overline{D C}$ & $\mathrm{DH}$ & $\overline{\mathrm{AN}}$ & P1000 & $\overline{D G}$ & NAC & PROD \\
\hline & \multicolumn{4}{|c|}{$(\mathrm{cm})$} & $\overline{(\mathrm{mm})}$ & (\%) & (g) & $\left(\mathrm{kg} \mathrm{m}^{-3}\right)$ & & $\left(\mathrm{kg} \mathrm{ha}^{-1}\right)$ \\
\hline Helio 250 & $32,1 \mathrm{a}$ & $160,6 \mathrm{~b}$ & $166,0 \mathrm{~b}$ & $14,7 \mathrm{a}$ & $16,9 \mathrm{a}$ & $89,6 \mathrm{a}$ & $34,1 \mathrm{a}$ & $245,1 \mathrm{a}$ & $823,1 \mathrm{~b}$ & $1436,2 b$ \\
\hline Helio 251 & $30,9 \mathrm{a}$ & $179,5 \mathrm{a}$ & $184,9 \mathrm{a}$ & $15,5 \mathrm{a}$ & $17,1 \mathrm{a}$ & $90,2 \mathrm{a}$ & $33,9 a$ & $230,6 \mathrm{a}$ & $1122,8 \mathrm{a}$ & $1884,5 \mathrm{a}$ \\
\hline Helio 360 & $31,9 a$ & $163,7 \mathrm{~b}$ & $168,9 \mathrm{~b}$ & $15,1 \mathrm{a}$ & $17,7 \mathrm{a}$ & $89,3 \mathrm{a}$ & 24,8 b & $199,2 \mathrm{a}$ & $1117,2 \mathrm{a}$ & 1438,6 b \\
\hline Média & 31,6 & 167,9 & 173,3 & 15,1 & 17,2 & 89,7 & 30,9 & 225,0 & 1021,1 & 1586,5 \\
\hline
\end{tabular}

Os híbridos avaliados não apresentaram diferenças para o diâmetro da haste (Tabela 2). GUEDES FILHO et al. (2013) obtiveram valores médios do diâmetro de haste aos 80 dias após a semeadura, em torno de $11,5 \mathrm{~mm}$. PRADO \& LEAL (2006) e IVANOFF et al. (2010), avaliando a mesma característica na variedade Catissol-01 e de três cultivares de girassol na savana de Roraima, observaram valores médios de $15,4 \mathrm{~mm}$ e 12,2 $\mathrm{mm}$, respectivamente, sendo estes valores menores que os observados por este estudo.

Para a porcentagem de aquênios normais, não se verificou diferença significativa entre os híbridos. O percentual de grãos normais foi superior a $89 \%$, o que demonstra que todos os híbridos estudados possuem respostas favoráveis ao enchimento de grãos em baixas precipitações (Figura 1), com menos que $11 \%$ de grãos chochos. Aquênios com menor massa foram obtidos com o H360, sendo, portanto, significativamente inferior aos demais híbridos. AQUINO et al. (2013) obtiveram valores duas vezes superiores aos encontrados para os mesmos híbridos em população de 40 mil plantas ha ${ }^{-1}$, que pode ser justificado pela menor competição por planta, tendo assim melhor desenvolvimento. Os valores estão abaixo dos encontrados para outras regiões do País, mas semelhantes aos encontrados por CAPONE et al. (2012) e SANTOS et al. (2012), que estudaram os mesmos híbridos na região sul do Estado do Tocantins.

Os dados obtidos não estão de acordo com os resultados de CASTRO \& FARIAS (2005), que descrevem que capítulos bem desenvolvidos tendem a ter maior proporção de aquênios grandes e com maior peso. SILVA et al. (2009) observaram que o P1.000 aquênios é influenciado pela maior quantidade de fibra.

Não foi detectada diferença significativa entre os híbridos para densidade de grãos. AMORIM et al. (2008) relataram que houve diferença significativa entre a densidade e o DC, sugerindo que quanto maior o capítulo maior será o DGP. Os resultados encontrados por estes autores não estão de acordo com os obtidos neste trabalho.

Foi verificado para o híbrido H250 menor número de aquênios por capítulo, diferindo significativamente das demais cultivares. BRAZ \& ROSSETTO (2009), analisando o cultivo do girassol cv. EMBRAPA 122/ V-2.000, constataram que a produção média de aquênios por planta foi de 940 unidades, valor esse que diferiu da média obtida no presente trabalho, de 1.021,05.

O H251 obteve a maior produtividade de aquênios, em relação aos demais híbridos. VOGT et al. (2010), ao avaliar divergência genética entre cultivar, no norte catarinense, dos híbridos $\mathrm{H} 251$ e H360, obtiveram valor superior apenas para H360. Os mesmos autores associaram o maior DC e P1.000, e elevado NAC, às maiores produtividades.

AMORIM et al. (2008) relataram que existem efeitos significativos entre produtividade de grãos, diâmetro do capítulo, porcentagem de grãos normais e a massa de mil grãos. LEMOS \& VAZQUEZ (2005), estudando os híbridos H250 e $\mathrm{H} 251$, no período de safrinha, obtiveram produtividades médias de grãos de 2.828,7 e $1.050,8 \mathrm{~kg} \mathrm{ha}^{-1}$, respectivamente, o que contraria os resultados encontrados no presente trabalho, para os mesmos híbridos, com relação inversa de produtividade, semelhante ao encontrado por LEITE \& CARVALHO (2005), que obtiveram produtividades médias de grãos de $1.682 \mathrm{e}$ $1.839 \mathrm{~kg} \mathrm{ha}^{-1}$, respectivamente.

$\mathrm{O}$ efeito do $\mathrm{N}$ sobre AP foi mais bem descrita por modelo linear (Figura 2A), influenciando significativamente todos os híbridos. Segundo ZAGONEL \& MUNDSTOCK (1991), a altura da planta é reflexo das condições nutricionais no período de alongamento do caule. Com a aplicação do N, o híbrido H251 apresentou valores de altura superiores aos demais. Os híbridos $\mathrm{H} 250$ e H360 obtiveram a mesma tendência para o efeito das doses de $\mathrm{N}$ na AP, resultados semelhantes aos observados por SILVA et al. (2007). 
A.

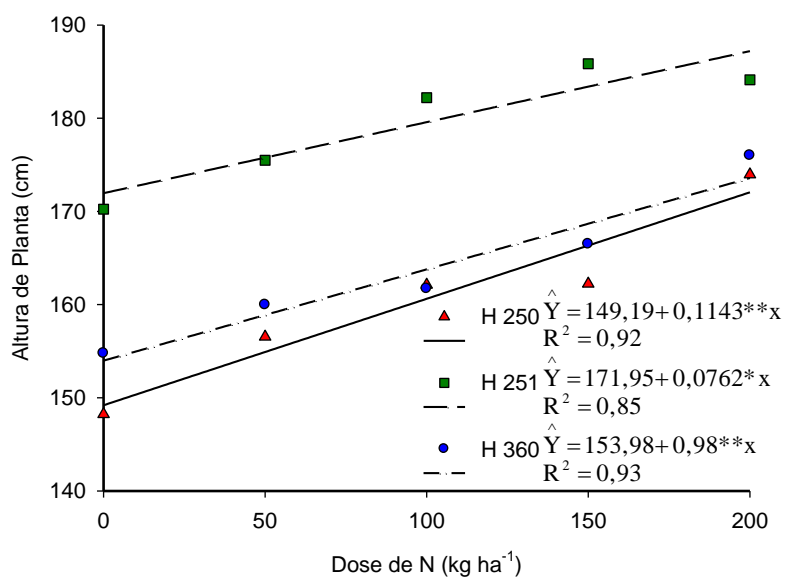

c.

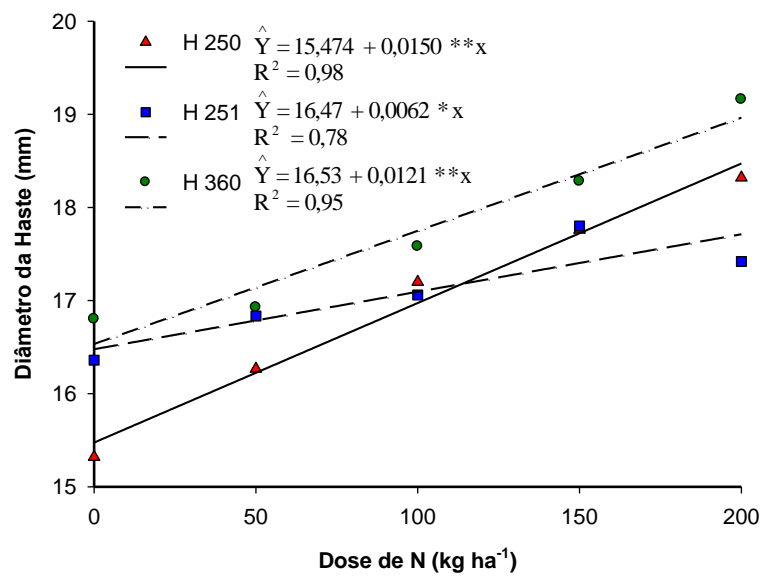

B.

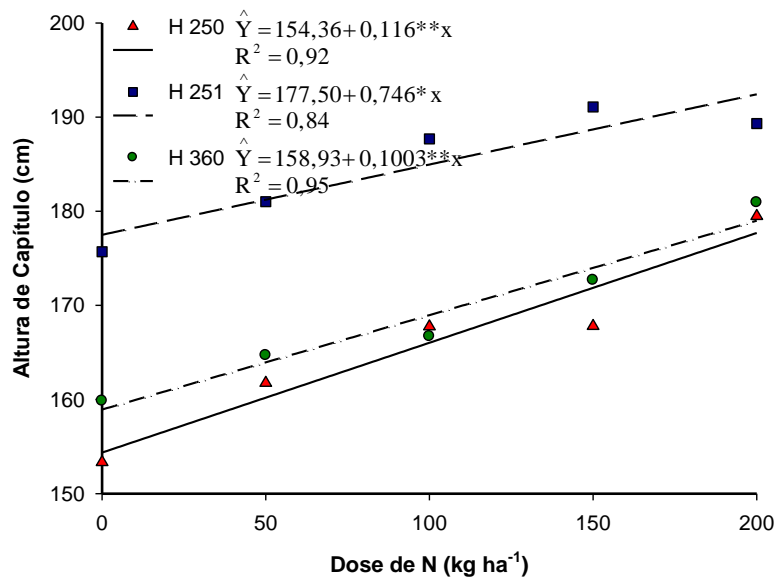

D.

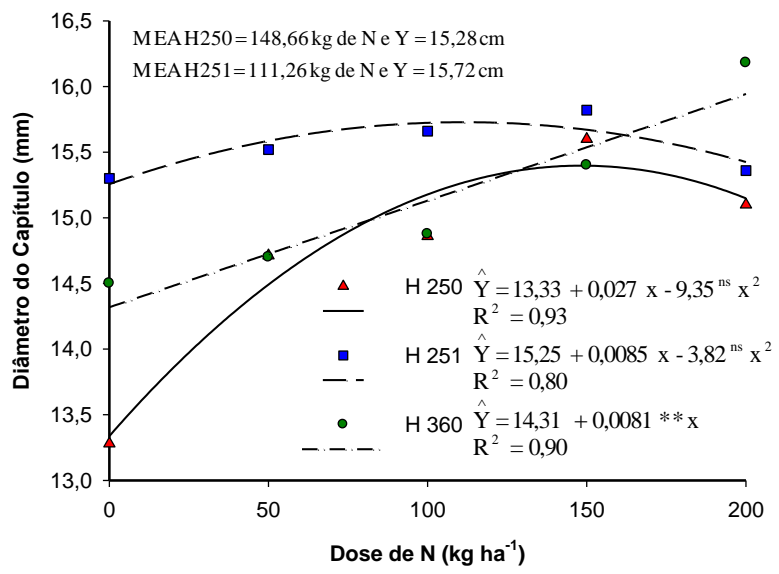

E.

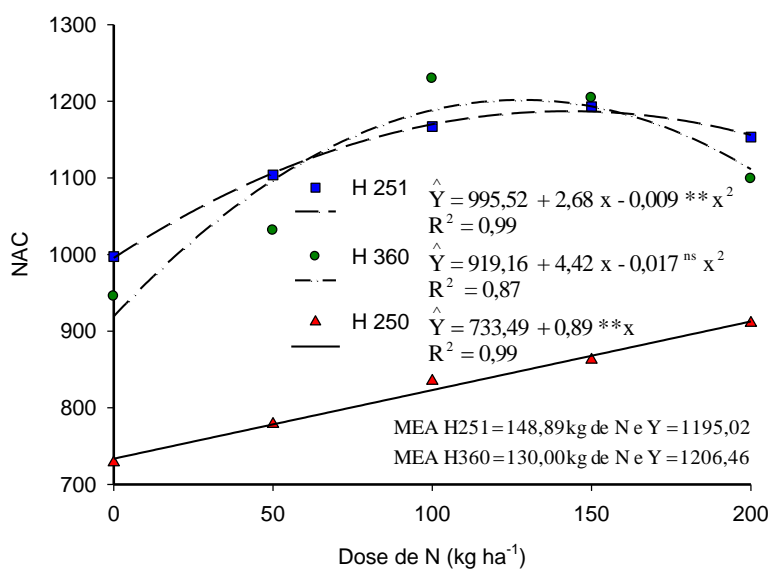

Figura 2 - Altura da planta (A); altura do capítulo (B); diâmetro da haste (C); diâmetro do capítulo, número de aquênios (E); das plantas de girassol, em função das doses de Nitrogênio. UFT, Gurupi TO, 2013. Plant height $(A)$, chapter height $(B)$, stem diameter $(C)$, chapter diameter, number of achenes (E), of sunflower plants in function of doses of nitrogen. UFT, Gurupi - TO, 2013. 
Os resultados encontrados por SANTOS et al. (2012) com girassol semeado em diferentes épocas condizem com os valores observados neste trabalho. Concordam com os resultados obtidos por FAGUNDES et al. (2007) no desenvolvimento de girassol ornamental, os quais demonstraram que as maiores doses de $\mathrm{N}$ proporcionaram maior altura de planta. Resultados divergentes para a AP foram encontrados por BARNI et al. (1995), IVANOFF et al. (2010) e GUEDES FILHO et al. (2013), que não encontraram efeitos significativos para essa variável, estudando doses de $\mathrm{N}$ em girassol. JONER et al. (2011) obtiveram valores inferiores para H250 e $\mathrm{H} 360$.

Verificou-se efeito significativo para a característica altura de capítulo (Figura 2B), sendo o modelo linear que melhor se ajustou para essa característica, obedecendo às mesmas tendências de altura de planta (Figura 2A).

$\mathrm{O}$ diâmetro da haste (Figura $2 \mathrm{C}$ ) dos híbridos teve comportamento significativo com ajuste linear em função das doses de $\mathrm{N}$. O híbrido H360 apresentou maior diâmetro da haste em relação ao H250 e H251. O H250 é menos responsivo em baixa disponibilidade de $\mathrm{N}$; contudo, com a elevação da dose do nutriente, mostrou respostas satisfatórias. O H251 teve resposta intermediaria para $\mathrm{DH}$, com diferença significativa a $(p \leq 0,05)$.

Para diâmetro de capítulo (Figura 2D), o híbrido H 360 obteve melhor ajuste para os dados, sendo representado pelo modelo linear, sendo bem responsivo ao efeito das doses. $O$ melhor modelo matemático que se ajustou para H251 e H250 foi o polinomial quadrático, contudo não houve efeito significativo em função das doses estudadas.

SOUZA et al. (2010) citam que a variável diâmetro do capítulo é um dos componentes de produção mais sensíveis à presença de nitrogênio, e em pequenas doses responde significativamente. BISCARO et al. (2008), avaliando diferentes doses de $\mathrm{N}$ na cultura do girassol irrigado, obtiveram resposta em que até a dosagem de $44,9 \mathrm{~kg} \mathrm{ha}^{-1}$ proporcionou bom ganho no diâmetro do capítulo. Segundo LOBO \& GRASSI FILHO (2007), o diâmetro do capítulo possui fatores positivos sobre número potencial de aquênios e com o aumento gradual do diâmetro aumentará o número de aquênios normais, que é componente essencial da produtividade.

O NAC obteve equações lineares e quadráticas (Figura 2E). Para H250, o modelo que melhor se ajustou aos dados foi o linear crescente. O H251 e o H360 apresentaram efeito quadrático. O H251 obteve valor superior a H360 em dose até $50 \mathrm{~kg} \mathrm{ha}^{-1}$ com efeito significativo ( $\mathrm{p}$ $\leq 0,01$ ). Acima de $148,89 \mathrm{~kg} \mathrm{ha}^{-1}$, houve um decréscimo para este híbrido. O H360 apresen- tou bom desempenho entre as doses de 50 a $150 \mathrm{~kg} \mathrm{ha}^{-1}$ de $\mathrm{N}$ com máxima eficiência agronômica de $130 \mathrm{~kg} \mathrm{ha}^{-1}$, porém não teve efeito significativo para doses crescentes de $\mathrm{N}$. De acordo com MERCAU et al. (2001), o número de aquênios por capítulo é um parâmetro adequado para se avaliar o rendimento do girassol. Reflete a ação dos nutrientes na fase crítica de diferenciação floral, que determina o número potencial de flores (ZAGONEL \& MUNDSTOCK, 1991).

\section{Conclusões}

A adubação nitrogenada influenciou sobre as características altura da planta, altura da capítulo, diâmetro da haste, diâmetro do capitulo e número de aquênios por capítulo.

O H251 obteve características agronômicas favoráveis para a produção no Estado do Tocantins, obtendo destaque em produtividade.

\section{Referências}

ALVAREZ, V. V. H.; ALVAREZ, G. A. M. Comparações de médias ou testes de hipóteses? Contrastes! Boletim Informativo da SBCS, Viçosa, MG, v.31, p.24-34, 2006.

AMORIM, E. P.; RAMOS, N. P., UNGARO, M. R. G., \& KIIHL, T. A. Correlações e análise de trilha em girassol. Bragantia, Campinas, v.67, n.2, p.307-316, 2008.

ANDRADE, F. H.; CALVINO, P.; CIRILO, A.; BARBIERI, $P$. Yield responses to narrow rows depend on increased radiation interception. Agronomy Journal, Madison, v.94, p.975-980, 2002.

AQUINO, L. A.; SILVA, Fred D. B.; BERGER, P. G. Características agronômicas e o estado nutricional de cultivares de girassol irrigado. Revista brasileira engenharia agrícola ambiental, Campina Grande, v.17, n.5, maio 2013. Disponível em: $<$ http://www.scielo.br/scielo.php?script=sci_arttext\& pid $=$ S1415-

43662013000500013\&lng=pt\&nrm=iso >. Acesso em: 24 jun. 2013.

BARNI, N. A.; BERLATO, M. A.; SANTOS, A. O. Análise de crescimento do girassol em resposta a cultivares, níveis de adubação e épocas de semeadura. Pesquisa Agropecuária Gaúcha, Porto Alegre, v.1, p.167-184, 1995.

BISCARO G. A.; MACHADO, J. R.; TOSTA, M. DA S.; MENDONÇA, V.; SORATTO, R. P.; CARVALHO, L. A. de. Adubação nitrogenada em cobertura no girassol irrigado nas condições de Cassilândia-MS, Ciência e Agrotecnologia, Lavras, v.32, n.5, p.1366-1373, 2008. 
BRAZ, M. R. S.; ROSSETTO, C. A. V. Acúmulo de nutrientes e rendimento de óleo em plantas de girassol influenciados pelo vigor dos aquênios e pela densidade de semeadura. Semina: Ciências Agrárias, Londrina, v.31, p.1193-1204, 2010.

BRAZ, M. R. S.; ROSSETTO, C. A. V. Estabelecimento de plântulas e desempenho de plantas em resposta ao vigor dos aquênios de girassol. Ciência Rural, Santa Maria, v.39, n.07, p.19972003, 2009.

CADORIN, A. M. R.; SOUZA, V. Q.; MANFRON, P. A.; CARON, B. O.; MEDEIROS, S. L. P. Características de plantas de girassol, em função da época de semeadura, na Região Noroeste do Rio Grande do Sul. Ciência Rural, Santa Maria, v.42, n.10, 2012. Disponível em: <http://www.scielo.br/scielo.php?script=sci_arttext\&pi $\mathrm{d}=$ S0103- 4782012001000004\&lng=en\&nrm=iso> Acesso em: 24 jun. 2013.

CAPONE, A.; SANTOS, E. R.; FERRAZ, E. C.; SANTOS, A. F.; OLIVEIRA, J. L.; BARROS, H. B. Desempenho agronômico de cultivares de girassol no sul do Estado Tocantins. Journal of Biotechnology and Biodiversity, Gurupi, v.3, n.3, 2012.

CARVALHO, D. B.; PISSAIA, A. Cobertura nitrogenada em girassol sob plantio direto na palha. Scientia Agrária, Curitiba, v.1/2, p.41-45, 2002.

CASTRO, C.; CASTIGLIONI, V. B. R.; BALLA, A.; LEITE, R. M. V. B. C.; MELLO, H. C.; GUEDES, L. C. A.; FARIAS, J. R. A cultura do girassol. Londrina: Embrapa-CNPSo, 1996. 38p. (Circular Técnica, 13)

CASTRO, C.; FARIAS, J. R. B. Ecofisiologia do girassol. In: LEITE, R. M. V. B. C.; BRIGHENTI, A. M.; CASTRO, C. (Ed.). Girassol no Brasil. Londrina: Embrapa Soja, 2005. p.163-218.

CONAB-Companhia Nacional de Abastecimento. Acompanhamento de safra brasileira: grãos: quarto levantamento. 2013. Disponível em: http://www.conab.gov.br/OlalaCMS/uploads/arqui vos/13 0709090453 boletim graos junho 2013.pdf>. Acesso em: 22 ago. 2013.

CRUZ, C. D. Programa Genes: Estatística experimental e matrizes. Viçosa: Editora UFV, 2006. 285p.

EMBRAPA - Empresa Brasileira de Pesquisa Agropecuária. Centro Nacional de Pesquisa de Solos. Sistema brasileiro de classificação de solos. 3.ed. Rio de Janeiro: EMBRAPA, 2006. $306 p$.

EMBRAPA. Manual de métodos de análise de solo. 2.ed.rev.atual. Rio de Janeiro: EMBRAPA, 1997. 212p.
FAGUNDES, J. D.; SANTIAGO, G.; MELLO, A. M. DE; BELLÉ, R. A.; STRECK, N. A. Crescimento, desenvolvimento e retardamento da senescência foliar em girassol de vaso (Helianthus annuus L.): Fontes e doses de nitrogênio. Ciência Rural, Santa Maria, v.37, p.987993, 2007.

GUEDES FILHO, H. D.; SANTOS JÚNIOR; J. A.; CHAVES, L. H. G.; CAMPOS, V. B.; OLIVEIRA, J. T. L. Água disponível no solo e doses de nitrogênio no crescimento do girassol. Revista Brasileira de Agricultura Irrigada, Fortaleza, v.7, n.3, p.201 - 212, 2013.

IVANOFF, M. E. A.; UCHÔA, S. C. P.; ALVES, J. M. A.; SMIDERLE, O. J.; SEDYAMA, T. Formas de aplicação de nitrogênio em três cultivares de girassol na savana de Roraima. Revista Ciência Agronômica, Fortaleza, v.41, n.3, p.319-325, 2010.

JONER, G; METZ, P. A. M.; ARBOITTE, M. Z.; PIZZUTI, L. A. D.; BRONDANI, I. L.; RESTLE, J. Aspectos agronômicos e produtivos dos híbridos de girassol (Helianthus annuus L.) Helio 251 e Helio 360. Ciência Animal Brasileira, Goiânia, v.12, n.2, p.266-273, 2011.

LEITE, R. M. V. B. C.; CARVALHO, C. G. P. Avaliação da resistência de genótipos de girassol à mancha de Alternaria (Alternaria helianthi) em condições de campo. In: REUNIÃO NACIONAL DE PESQUISA DE GIRASSOL, 16.; SIMPÓSIO NACIONAL SOBRE A CULTURA DO GIRASSOL, 4., 2005, Londrina. Anais... Londrina: Embrapa Soja, 2005. p.108-110.

LEMOS, D. M. R.; VAZQUEZ, G. H. Comportamento agronômico de diferentes genótipos de girassol na época da safrinha em Fernandópolis/SP. In: REUNIÃO NACIONAL DE PESQUISA DE GIRASSOL, 16.; SIMPÓSIO NACIONAL SOBRE A CULTURA DO GIRASSOL, 4., 2005, Londrina. Anais... Londrina: Embrapa Soja, 2005. p.76-79.

LOBO, T. F.; GRASSI FILHO, H. Níveis de lodo de esgoto na produtividade do girassol. Revista Ciencia del Suelo e Nutricíon Vegetal, Temuco, v.7, n.3, p.16-25, 2007

LOPES, P. V. L.; MARTINS, M. C.; TAMAI, M. A.; OLIVEIRA, A. C. B.; CARVALHO, C. G. P. DE. Produtividade de genótipos de girassol em diferentes épocas de semeadura no oeste da Bahia. Pelotas: Embrapa Clima Temperado, 2009. 4p. (Comunicado Técnico, 208).

MELLO, R.; NÖRNBERG, J. L.; RESTLE, J. et al. Características fenológicas, produtivas e qualitativas de híbridos de girassol em diferentes épocas de semeadura para produção de silagem. Revista Brasileira de Zootecnia, Viçosa, MG, v.35, n.3, p.672-682, 2006. 
MERCAU, J. L.; SADRAS, V. O; SATORRE, E. H.; MESSINA, C.; BAIBI, C.; URIBELARREA, M.; HALL, A. J. On-farm assessment of regional and seasonal variation in sunflower yield in Argentina. Agricultural Systems, Essex, v.67, n.2, p.83103, 2001.

OLIVEIRA, F. A.; CASTRO, C.; FRANCHINI, J. C.; TORRES, E. Manejo do solo. In: LEITE, R. M. V. B. C.; BRIGHENTI, A. M.; CASTRO, C. (Ed.). GIRASSOL NO BRASIL. Londrina: Embrapa Soja, 2005. p.299-316.

PRADO, R. M; LEAL, R. M. Desordens nutricionais por deficiência em girassol var. catissol -01 . Pesquisa Agropecuária Tropical, Goiânia, v.3, n.36, p.187-193, 2006.

RAJKOVIC, Z.; VREBALOV, T.; BOGDANOVIC, $D$. Method of nitrogen fertilization and yield of sunflower hybrid NS-H-26-RM. In: CONFERÊNCIA INTERNACIONAL DE GIRASOL, 9, 1980, Torremolinos. Cordoba: Instituto Nacional de Investigações Agrárias, 1980. T.2, p.192-196.

SANTOS, E. R.; BARROS, H. B.; CAPONE, A.; FERRAZ, E. C.; FIDELIS, R. R. Efeito de épocas de semeadura sobre cultivares de girassol, no Sul do Estado do Tocantins. Revista Ciência Agronômica. Fortaleza, v. 43, n. 1, Mar. 2012. Disponível em: <http://dx.doi.org/10.1590/S180666902012000100025 >. Acesso em 28 set. 2013.
SIGMAPLOT. Scientific Graphing Software. Version 10.0. 2007.

SILVA, A. G.; PIRES, P.; MORÃES, E. B.; OliveiRA, A. C. B.; CARVALHO, C. G. P. Desempenho de híbridos de girassol em espaçamentos reduzidos. Semina: Ciências Agrárias, Londrina, v.30, n.01, p.31-38, 2009.

SILVA, M. L. O.; FARIA, M. A.; MORAIS, A. R.; ANDRADE, G. P.; LIMA, E. M. C. Crescimento e produtividade do girassol cultivado na entressafra com diferentes lâminas de água. Revista Brasileira de Engenharia Agrícola e Ambiental, Campina Grande, v.11, p.482- 488, 2007.

SILVA, P. S. L.; SILVA, P. I. B. Parcelamento da adubação nitrogenada e rendimento de espigas verdes de milho. Horticultura Brasileira, Brasília, v.21, n.01, p.150-153, 2003.

SOUZA, R. M.; NOBRE, R. G.; GHEYI, H. R.; DIAS, N. DA S.; SOARES, F. A. L. Utilização de água residuária e de adubação orgânica no cultivo do girassol. Caatinga, Mossoró, v.23, p.125133, 2010.

ZAGONEL, J.; MUNDSTOCK, C. M. Doses e épocas de aplicação de nitrogênio em cobertura em duas cultivares de girassol. Pesquisa Agropecuária Brasileira, Brasília, v.26, p.14871492, 1991. 